\title{
NOTAS ESCRITAS EM UM ÁTICO: AUTOBIOGRAFIA DE EMMA LAVINIA HARDY
}

\author{
NOTES WRITEEN IN AN ATTIC: EMMA LAVINIA HARDY'S \\ AUTOBIOGRAPHY
}

Maria de Fátima de Almeida BAIA ${ }^{1}$

All matters its long years resolving

To sweetness and light

Emma Lavinia Hardy em Ten moons (1907)

\begin{abstract}
Resumo: Neste estudo, visitamos os diários e a autobiografia da primeira esposa de um escritor inglês ilustre, Thomas Hardy. Emma Lavinia Hardy nos apresenta por meio dos seus diários de viagem e a sua autobiografia Some Recollections, escrita um ano antes da sua morte, a sua visão sobre o amor, as inseguranças de uma mulher da era vitoriana, seu misticismo repleto de sincretismo, suas visitas aos túmulos de poetas famosos e outros personagens históricos, além do poder que a música teve na sua união com Thomas Hardy. Acompanhamos sua voz por meio de um olhar da Psicologia Analítica e da literatura sobre autobiografia, destacando as memórias escritas em um ático, onde passou os últimos anos da sua vida, em uma casa de campo em Dorset na Inglaterra.
\end{abstract}

Palavras-chave: Thomas Hardy. Emma Lavinia Hardy. Autobiografia. Diários.

Abstract: In this study, we visit the diaries and the autobiography of the first wife of an illustrious English writer, Thomas Hardy. Emma Lavinia Hardy introduces us through her traveldiaries and her autobiography Some Recollections, written a year before her death, her vision on love, on the insecurities of a Victorian woman, on her mysticism full of syncretism, on her visits to the tombs of famous poets and other historical characters, and the power that music had in her union with Thomas Hardy. We follow her voice by using a view from the Analytical Psychology as well as the Autobiography Literature, highlighting the memoirs written in an attic where she spent the last years of her life, at a cottage in Dorset in England.

Keywords: Thomas Hardy; Emma Lavinia Hardy; Autobiography; Diaries.

\section{Introdução}

Emma Lavinia Gifford nasceu no dia 24 de novembro de 1840, no mesmo ano do seu futuro marido, em Plymouth, na Inglaterra. Filha de integrantes da classe média ascendente inglesa, desde pequena, mostrou fascínio por música e por literatura, sendo a segunda marcante

\footnotetext{
${ }^{1}$ Doutora em Linguística pela Universidade de São Paulo (Brasil). Professora Adjunta do Programa de PósGraduação em Linguística (PPGLin) e do Departamento de Estudos Linguísticos e Literários da Universidade Estadual do Sudoeste da Bahia. mariadefatimabaia@uesb.edu.br.
} 
na personalidade do renomado escritor inglês Thomas Hardy, autor de obras como A pair of blue eyes (1873), Far from the Madding Crowd (1874), The Woodlanders (1887), Jude the obscure (1895), entre outras.

Neste estudo, apresentamos características de quem até então tem sido tratada como uma sombra de Thomas Hardy, alguém que, embora tenha escrito duas obras autobiográficas, poemas, ensaios místicos e iniciado um romance, tem sido descrita pela literatura, que aborda a obra de Hardy, como a primeira esposa de um casamento infeliz (KAY-ROBINSON, 1979; TAYLOR, 1985), a esposa arrogante que queria ter os créditos das obras do esposo (BAILEY, 1966; TAYLOR, 1985), a esposa que apresentou sinais de insanidade junto com fanatismo religioso (KAY-ROBINSON, 1979), entre outras. É importante mencionarmos que grande parte da alegação de insanidade da Emma Hardy, nos seus últimos anos, vem das cartas trocadas por Florence Dugdale, secretária e segunda esposa de Hardy, com uma amiga. Além disso, tais alegações ocorreram por parte da segunda esposa, após a morte de Emma Hardy e da escrita da obra poética Poems of 1912-1913, por Thomas Hardy. Na obra, o escritor revive o romance com sua primeira esposa, embora já casado com a segunda, por meio de versos repletos de remorso e saudade. Por fim, o fato de Emma Hardy defender a existência da sua autoria em obras de Thomas Hardy não parece ser tão infundado, pois, segundo Manford (2005, p. XXXIX), há a presença da caligrafia de Emma Hardy em diversas páginas do primeiro romance do marido, A pair of blue eyes, o que, segundo o autor, levanta dúvidas a respeito da autoria absoluta ser dele.

Todavia, nosso intuito, neste estudo, não é apresentar provas por meio dos diários e cartas de Emma Hardy que confirmem ou não o que tem sido afirmado até então pela literatura prévia. Nosso intuito é apresentar, por meio da sua própria voz presente nos seus diários (1985) e na sua obra autobiográfica, Some Recollections (1961 [1911]) - com base em uma literatura sobre autobiografia (EAKIN, 1985; 1999; 2004; LARROSA, 2004; ABRAÃO, 2004; BELZEN; GEELS, 2008) e uma leitura via Psicologia Analítica (JUNG, 1984; 1987; STEIN, 2003) dos seus relatos -, lados que têm sido ignorados pela literatura até então: o seu misticismo, o papel do julgamento da sociedade a respeito da aparência da mulher no século XIX, e a sua releitura sobre o seu romance com Thomas Hardy. Destacamos no título deste estudo a palavra ático por ter sido o local onde Emma Hardy passou seus últimos anos de vida, escrevendo suas memórias, seus ensaios místicos e suas tristezas a respeito de um marido ausente, embora esse último lado 
das memórias tenha sido queimado por Thomas Hardy após a morte da esposa: “[...] Hardy destruiu a parte de Recollections que descrevia a sua vida de casada" (BAILEY, 1966, p. 2)².

\title{
A escrita autobiográfica e os diários
}

Segundo Belzen e Geels (2008), as culturas ocidentais têm se tornado culturas autobiográficas de maneira considerável nas últimas três décadas. Segundo o autor, a autobiografia se tornou uma arena pública de confissão e de retrato da vida interna, não apenas em estudos culturais ou literários:

\begin{abstract}
Ao contrário do que acontecia duas ou três décadas atrás, a maior parte da pesquisa sobre memória hoje - seja na Psicologia ou nas Neurociências, seja nas Ciências Sociais ou nos estudos Culturais - confirma a afirmação de que o que lembramos e como lembramos depende primeiramente das circunstâncias presentes nas quais nós lembramos. Embora as narrativas autobiográficas sejam tipicamente vistas como narrativas sobre o passado, elas são também sobre o presente (BELZEN; GEELS, 2008 , p. 21, tradução nossa) $)^{3}$.
\end{abstract}

No que se refere à afirmação de Belzen e Geels a respeito do aspecto multidisciplinar da narrativa autobiográfica, podemos complementá-la com a afirmação de Eakin (1999). O autor propõe que podemos repensar a tarefa de analisar a natureza da autoexperiência por meio da autobiografia, o que tem sido corroborado, segundo ele, por estudos da Neurologia, Ciências Cognitivas e campos relacionados. No que se refere à afirmação de Belzen e Geels (2008) de que o relato sobre o passado é influenciado pela situação do presente, observamos isso na obra Some Recollections (1961 [1911]) de Emma Hardy, na qual ela revive o início do romance e os primeiros anos de casamento com Hardy trinta anos depois. Todavia, o mesmo não pode ser dito a respeito dos quatro diários reunidos na obra Emma Hardy Diaries (1985), pois foram escritos quase que imediatamente a cada situação vivenciada, como se a autora quisesse fotografar cada momento por meio de descrição e narrativa. Os quatro diários descrevem visitas com seu esposo a países estrangeiros e suas impressões: 1) Visita à França de setembro a outubro de 1874; 2) Visita à Holanda de maio a junho de 1876; 3) Visita à Itália de março a abril de 1887; 4) Visita à Suíça de junho a julho de 1897.

\footnotetext{
2 [...] Hardy destroyed the portion of Emma's Recollections that described her married life. (BAILEY, 1966, p. 2).

${ }^{3}$ Unlike two or three decades ago, most research on memory today - be it in psychology or the neurosciences, be it in the social sciences or cultural studies - confirms the claim that what we remember and how we remember depends primarily on the present circumstances in which we remember. Although autobiographical narratives are typically seen as narratives about the past, they are at least as much about the present (BELZEN; GEELS, 2008, p. 21).
} 
No entanto, independente de ter sido escrito minutos ou anos depois, segundo Belzen e Geels (2008), mesmo em relatos como de diário, encontramos a presença de memória autobiográfica, identidade, tempo, entre outros aspectos. Como será apresentado a seguir, os relatos dos diários de Emma Hardy, muitas vezes, trazem testemunhos a respeito de lugares e pessoas, característicos também da escrita autobiográfica, segundo Mosquera e Stobäus (2004). Em adição, segundo Popkin (2004), a escrita de diários seria mais livre, permitindo ao leitor acompanhar um amadurecimento e mudança da escrita do autor, como veremos com exemplos dos diários de Emma Hardy.

Some Recollections, por ter sido escrito em 1911, um ano antes da sua morte, em 1912, demonstra uma necessidade que Emma Hardy sentiu de apresentar sua própria interpretação da sua história de vida. Além disso, segundo Eakin (1985, p. 9), o impulso para escrever autobiografia é uma forma especial da nossa consciência reflexiva, um traço distintivo da nossa natureza humana.

O ser humano é um ser que se interpreta e, para essa autointerpretação, utiliza fundamentalmente formas narrativas. A partir de então, pode-se pensar a relação entre essa misteriosa entidade que é o sujeito (o sujeito da autoconsciência, mas também o sujeito da intersubjetividade; o sujeito pessoal, mas também o sujeito social, o sujeito histórico, o sujeito cultural etc.) e esse particular e quase onipresente gênero discursivo que é a narrativa (LARROSA, 2004, p. 12, tradução nossa) ${ }^{4}$.

Dessa maneira, como veremos com excertos dos seus escritos, ao apresentar-nos a sua narrativa de vida, Emma Hardy apresenta-nos o sentido que ela, naquele momento, atribuía ao que viveu e ao que era, pois “[...] o que somos não é outra coisa que o modo como nos compreendemos; o modo como nos compreendemos é análogo ao modo como construímos textos sobre nós mesmos" (LARROSA, 2004, p. 14) $)^{5}$. Ademais, ao abrir a janela da sua memória, a autora mostra-nos como determinados acontecimentos a tocaram, o que viu, o que percebeu e sua própria coloração; aspectos, segundo Bois e Rugira (2016), fundamentais na escrita autobiográfica.

\footnotetext{
${ }^{4}$ El ser humano es un ser que se interpreta y, para esa auto interpretación, utiliza fundamentalmente formas narrativas. A partir de ahí, se puede pensar la relación entre esa misteriosa entidade que es el sujeto (el sujeto de la autoconsciencia, pero también el sujeto de la intersubjetividad; el sujeto personal, pero también el sujeto social, el sujeto histórico, el sujeto cultural, etc) y ese particular y casi omnipresente género discursivo que es la narrativa (LARROSA, 2004, p. 12).

5 [...] Lo que somos no es outra cosa que el modo como nos comprendemos; el modo como nos comprendemos es análogo al modo como construímos textos sobre nosotros mismos (LARROSA, 2004, p. 14).
} 


\section{Os diários e a autobiografia de Emma Hardy}

Segundo Taylor (1985), responsável pela organização dos diários de Emma Hardy e pela introdução, as notas da autora podem ser caracterizadas, de maneira geral, como notas de viagem por enfatizarem quatro viagens feitas ao exterior com o esposo. $\mathrm{O}$ autor ressalta que a obra, publicada mais de setenta anos depois da morte de Emma Hardy, veio balancear uma imagem que permanecia negativa da esposa de Hardy:

[...] quando a opinião recebida a respeito da existência da Emma era a de que ela tinha sido uma esnobe desagradável que sentia inveja dos talentos do marido e desdém da sua visão moral e social, gradualmente se tornando insana. Nos anos recentes, a injustiça dessa visão simplista tem se tornado clara, e os diários de viagem reproduzidos neste volume nos ajudam [...] a nos direcionar para uma perspectiva mais balanceada (TAYLOR, 1985, p. 8, tradução nossa) ${ }^{6}$.

Como dito anteriormente, tal fama foi propagada pela segunda esposa de Hardy, com ciúmes do marido, que lamentava por um amor perdido e sentia remorso pela morte da sua primeira esposa. Além dessas alegações, Florence Dugdale propagava, por meio das cartas para amiga, que a Emma Hardy "tinha se jogado para cima" do Thomas, o que, segundo KayRobinson (1979), não faz sentido, pois, quando Emma conheceu Thomas Hardy, quando ambos tinham 29 anos, ele não passava de um arquiteto sem muito a oferecer. Como veremos nos trechos de Some Recollections - e está na própria poesia de Thomas Hardy dedicada para a esposa falecida -, o sentimento que os uniu foi mútuo e verdadeiro, mesmo que, com o passar dos anos, o casamento tenha se deteriorado.

\section{A Emma Hardy do primeiro diário: Lua de Mel na França - setembro a outubro de 1874}

Neste primeiro diário, vemos uma Emma preocupada em descrever cenários da França e, em especial, a culinária do país. Não apresenta detalhes da lua de mel no cenário mais íntimo do casal. Como dito anteriormente, trata-se de uma escrita "fotográfica" do que ela vê, apoiada por desenhos que ela fazia com maestria assim como quadros à tinta óleo.

\footnotetext{
${ }^{6}[\ldots]$ when the received opinion of Emma's life-course came to be that she had been a disagreeable snob who, jealous of her husband's talents and disdainful of his social and moral views, gradually became insane. In recent years the unfairness of this glib view has become clear, and the travel diaries reproduced in this volume help us $[\ldots]$ towards a more balanced perspective (TAYLOR, 1985, p. 8).
} 
Segunda-feira, dia 28 de setembro - túmulo de Napoleão I. Um poço de mármore circular. Você se inclina na borda e olha para o sarcófago cor de chocolate. [Esboço] bandeiras tomadas por Napoleão (TAYLOR, 1985, p. 37, tradução nossa) ${ }^{7}$.

Além do túmulo de Napoleão, Emma e Thomas Hardy visitaram o túmulo de Balzac, do qual Emma pegou uma folha seca e guardou em seu diário, o que começa a demonstrar o seu fascínio por folhas e flores secas.

Adiante, vemos nas notas uma preocupação com sua aparência, uma sensação de que seria considerada uma mulher "estranha" para o povo francês:

Onde quer que eu vá, quem quer que eu passe - a qualquer hora do dia ou da noite -
as pessoas olham para mim tanto ou mais do que eu olho para elas e sua linda cidade
- tão cheia de coisas estranhas, lugares - lojas - vestimentas - maneiras - Dúvida -
Eu sou uma pessoa de aparência estranha - ou meramente pitoresca neste chapéu -
As mulheres às vezes dão uma risadinha quando passam (TAYLOR, 1985, p. 40,
tradução nossa)

Nessas palavras, encontramos uma preocupação de uma mulher vitoriana viajante em terras estrangeiras, preocupada com a persona que representava pelas ruas francesas, i.e. com o papel cultural e pessoal que expressava com sua vestimenta e suas maneiras (BYINGTON, 1987). Segundo Byington (1987), na visão da Psicologia Analítica, a persona é um dos cinco principais arquétipos presentes na nossa composição como sujeito. Segundo Jung (1987, p. 32), ao analisarmos uma persona, dissolvemos uma máscara e, com isso, descobrimos que, embora pareça individual, ela é coletiva. Interessantemente, quando Emma questiona se o que causa estranhamento é o seu chapéu, marca feminina na cultura inglesa, ela, inconscientemente, mostra que por trás do aparentemente individual está um julgamento do coletivo que carrega.

\section{A Emma Hardy do segundo diário: descrevendo a visita à Holanda-maio a junho de 1876}

Assim como no primeiro diário, o segundo diário de Emma Hardy está repleto de descrições de lugares, comidas e, também, de pessoas. Algumas páginas, mais do que no primeiro, são acompanhadas por desenhos do que ela quer descrever. Ao contrário do primeiro, neste suas anotações parecem mais técnicas, ocultando uma percepção mais íntima a respeito

\footnotetext{
${ }^{7}$ Monday, $28^{\text {th }}$. Sep - Tomb of Napoleon I. A circular marble well. You lean on the edge \& look down upon a chocolate-coloured sarcophagus. [Sketch] flags taken by Napoleon (TAYLOR, 1985, p. 37).

${ }^{8}$ Wherever I go, whoever I pass - at whatever time daytime or by night - the people gaze at me as much or more than I at them \& their beautiful city - so full of strange things, places - shops - people dress - ways - Query - Am I a strange-looking person - or merely picturesque in this hat - Women sometimes laugh a short laugh as they pass (TAYLOR, 1985, p. 40).
} 
do que sente em terras estrangeiras, como, por exemplo, a descrição que faz das casas e janelas holandesas:

As casas são peculiares a esse respeito - uma grande quantidade de vidro, mas as janelas são bastante abundantes e se estendem assim como as janelas de lojas na Inglaterra - mas a estrutura grande e comprida sempre é branca e toda pintada de branco dentro e fora da casa (TAYLOR, 1985, p. 40, tradução nossa) ${ }^{9}$.

\section{A Emma Hardy do terceiro diário: descrevendo a visita à Itália - março a abril de 1887}

Assim como os dois primeiros diários, o terceiro pode ser descrito como um diário de viagem repleto de descrições de lugares, pessoas e costumes. Novamente, encontramos uma Emma preocupada com a questão da persona representada, agora não por ela, mas sim a presente nas mulheres italianas:

Em Gênova, grupos frequentes de mulheres em cores brilhantes, mas harmoniosas amarelo ou vermelho. Lenço na cabeça, vestido carmesim, xale vermelho escarlate ou mais claro nos outros azul escuro, azul claro, laranja, roxo, verde, 4 ou 5 mulheres (TAYLOR, 1985, p. 126, tradução nossa $)^{10}$.

Assim como na sua viagem para a França, Emma Hardy continuou mostrando fascínio por folhas e flores retirados de túmulos de pessoas que admira:

Recolhi violetas dos túmulos de Shelley e Keats. Lindo cemitério muito cheio. Lotado onde Shelley está, seu túmulo em um lugar isolado, um canto silencioso, mas não bonito, uma porta velha atrás [...] Palavras em lápide muito patéticas (TAYLOR, 1985 , p. 126, tradução nossa $)^{11}$.

A Emma Hardy do quarto diário: descrevendo a visita à Suíça - junho a julho de 1897

Trata-se do último diário que temos de Emma Hardy. Como os outros três diários, os relatos de viagem destacam-se ao longo das notas, apesar de ser mais curto do que os anteriores. Além disso, não há desenhos nas anotações desse diário. São notas rápidas e a sensação presente é de uma Emma um pouco entediada. Sabemos que, embora estivesse viajando com Thomas Hardy, os dois já estavam bem distantes em 1897, o que pode ter contribuído para o humor que

\footnotetext{
${ }^{9}$ Houses are peculiar in these respects - a great deal of glass but the windows rather plentiful than extending across the fronts as shop windows in England - yet large \& long frame works always white \& everything painted white that can be in the house \& outside (TAYLOR, 1985, p. 75).

${ }^{10}$ At Genoa frequent groups of women in brilliant yet harmonious colouring - yellow or red. Kerchief on head, crimson gown, scarlet shawl darker red, or brighter on others dark blue, light blue, orange, purple, green, 4 or 5 women [...] (TAYLOR, 1985, p. 126).

${ }^{11}$ Gathered violets off graves of Shelley \& Keats. Lovely cemetery very full. Crowded where Shelley is, his grave up in a place by itself, a quiet corner but not a pretty one, \& old door behind [...] Words on grave-stone very pathetic (TAYLOR, 1985, p. 145).
} 
observamos nas suas anotações. Além disso, pelas suas anotações, o marido não estava bem de saúde durante a viagem:

1 de julho. T.H. não está bem - almocei sozinha - em Genebra. Primeiro hotel (não bom). Consegui o remédio (óleo) para T.H. Deixei o hotel [...] Bela vista do lago. Tempo bom - T.H. melhor - nós saímos. Saí sozinha à noite para a ponte (TAYLOR, 1985, p. 126, tradução nossa) ${ }^{12}$.

Um aspecto que demonstra mudança na relação entre ela e o Thomas Hardy é a maneira que ela o chama no seu diário. No primeiro diário, na lua de mel, ele era o "Tom"; agora ela usa as iniciais do seu nome e sobrenome "T.H.".

Dessa maneira, apesar de enfatizar descrições de lugares, pessoas e costumes nos seus diários, Emma Hardy passa, mesmo que sutilmente, a mudança gradativa na sua relação com seu esposo, como também como que o brilho e empolgação dessas viagens com ele tendem a diminuir com o tempo.

A seguir, por meio da sua narrativa em Some Recollections, temos uma visão mais aprofundada da mulher que se apaixonou pelo grande escritor inglês e a memória dos dias bons que ela fez questão de registrar de acordo com a sua interpretação.

\section{Some Recollections (1911)}

Segundo Taylor (1985), vários incidentes relatados nas memórias de Emma Hardy em Some Recollections estão reproduzidos na visão de amor trágico na obra de Thomas Hardy, Poems of 1912-1913. Essa visão trágica, provavelmente inspirada pelas memórias de Emma Hardy, é reconhecida pelo próprio esposo:

O elegíaco Poems of 1912-1913 escrito, disse Hardy, como uma "expiação" em remorso por sua contribuição nas divisões passadas, recaptura, sob a epígrafe Veteris vestigial flammae "Cinzas do antigo fogo" de Eneida (TAYLOR, 1985, p. 8, tradução nossa) ${ }^{13}$.

\footnotetext{
${ }_{12}$ July 1. T.H. not well - lunched by myself - at Geneva. First hotel. (Not good.). Got medicine, (oil) for T. H.. Left hotel [...] Fine view of Lake. Fine weather - T.H. better - we walked out. I went out by myself in evening to bridge (TAYLOR, 1985, p. 207).

${ }^{13}$ The elegiac "Poems of 1912-1913" written, Hardy said, as "an expiation" in remorse for his contribution to their later divisions, recapture, under the epigraph "Veteris vestigial flammae" ("Ashes of the old fire") from the Aeneid [...] (TAYLOR, 1985, p. 8).
} 
Consta na versão original de Some Recollections anotações do próprio Hardy, que fez alterações mínimas na pontuação e inserindo ou trocando palavras. O que foi inserido ou alterado por Hardy aparecerá na transcrição com os sinais [ ].

Neste estudo, como dito anteriormente, prendemo-nos à visão de Emma Hardy a respeito da sua própria aparência, existência e romance com o ilustre autor. Vinda de uma família da classe média ascendente inglesa, filha de um pai alcoólatra, que ela ainda admirava pelo seu conhecimento literário, e filha de uma mãe religiosa, que ensinou hábitos incomuns de higiene para a época e quem a inspirou a cantar e tocar piano. O seu talento musical desempenhou um papel importante para atrair Thomas Hardy no início do romance. Além disso, foi um meio que ela usou tentando fazer as pazes no dia da sua morte, quando tocou no piano peças musicais que marcaram o início do romance dos dois, mas sua tentativa de reconciliação, talvez tendo a intuição de que não estaria viva ali no outro dia, não foi correspondida:

Na visão de que a parte da música tivesse sido um meio de atrair Hardy para Emma, de mantê-los juntos, e de suas tentativas de romper barreiras do estranhamento, não é sem interesse que ela lembrou dessas músicas e ares no dia da sua morte, incluindo outras que ela não menciona (KAY-ROBINSON, 1979, p. 10, tradução nossa) ${ }^{14}$.

Toda essa insistência por parte da Emma, horas antes da sua partida deste mundo, provavelmente foi resultado da sua crença de que existiria a pessoa certa, isto é, escolhida pelos céus, e esta pessoa seria o Thomas Hardy. Na sua autobiografia, ela comenta que ele estava no seu caminho, pois assim foi previsto por uma cigana e em um encantamento que fez com a sua irmã e amiga:

Em uma ocasião, minha sorte foi lida repentina e persistentemente por uma mulher
cigana, apesar de uma apreensão e objeção nervosas de minha parte. De repente, a
mulher cigana recomeçou do lado da estrada, um pouco fora de Bodmin, segurando-
me e fazendo-me ouvi-la - muito de sua profecia se tornou realidade, [e] ela não
possuía nenhuma moeda minha nem até mesmo um agradecimento - ela continuou
falando coisas lisonjeiras sobre mim depois. Duas vezes depois, minha sorte foi
contada de uma forma surpreendente por cartas que uma velha amiga da família
colocava misteriosamente [...] Em um desses copos colocados diante de nós, cada uma
quebrou um ovo, deixando o branco cair na água, depois observando que forma que
formaria, a qual significaria a ocupação de nossos futuros cônjuges. Minha irmã
começou o encanto ansiosamente [...] "Você vai se casar com um escritor", e foi o que
eu fiz! Agora, como esses ovos revelaram tudo? Um assunto muito misterioso aquele!
(HARDY, 1961 [1911], p. 39-41, tradução nossa) ${ }^{15}$.

\footnotetext{
${ }^{14}$ In view of the part music was to play in attracting Hardy to Emma, in holding them together, and in her attempts to break through the barriers of estrangement, it is not without interest to consider what those old songs and airs she remembered to the day of her death included in addition to those she mentions (KAY-ROBINSON, 1979, p. $10)$.

15 On one occasion my fortune was told suddenly and persistently by a gipsy woman, notwithstanding a nervous apprehension and objection on my part. The gipsy woman suddenly started up from the road-side, a little out of
} 
Mais adiante na sua obra, Emma Hardy descreve de uma maneira simples e profunda o início da história dos dois:

Fomos ficando interessandos um no outro, e eu enxerguei como um assunto perfeitamente novo de estudo e prazer, e ele encontrou uma 'minha' em mim, disse ele; ele era muito diferente de qualquer outra pessoa que veio nos ver, pois eram lentos na fala e nas ideias! (HARDY, 1961 [1911], p. 58, tradução nossa) ${ }^{16}$.

Além da ideia romântica de Emma a respeito de um amor escrito pelas estrelas, é intrigante que alguém como ela, que demonstra na sua autobiografia fascínio pelos dizeres ciganos, cartas de tarô e encantamentos, seja julgada como uma protestante fanática. Grande parte disso resultou das palavras nas cartas Florence Dugdale. Se há uma palavra para definir o misticismo de Emma Hardy seria, no mínimo, algo que tivesse o aspecto sincrético embutido. Segundo a própria autora:

Eu tenho alguma filosofia e misticismo, e uma crença ardente no Cristianismo e na vida além da presente, tudo o que torna qualquer existência curiosamente interessante (HARDY, 1961 [1911], p. 39-41, tradução nossa) ${ }^{17}$.

Todo esse sincretismo místico nada mais mostra a natureza humana de Emma Hardy, pois, segundo Jung (1987, p. 77), “[...] psique não é uma unidade e sim uma pluralidade contraditória de complexos [...]". Nesses relatos presentes na autobiografia de Emma Hardy, vemos o contraditório na expressão da sua espiritualidade, vemos o humano. A citação acima está presente no último parágrafo de Some Recollections. Nela, encontramos uma tentativa de sumarizar a sua visão a respeito do ato de existir.

Toda essa necessidade de apoio metafísico presente na narrativa de Emma Hardy não é algo incomum na vida de uma mulher que passa dos setenta anos. Na sua própria mocidade, como mostramos com trechos de diários, há presença de incerteza e insegurança, que acompanham o percurso existência. Na sua autobiografia, quando ela lembra a respeito da

Bodmin, catching hold of my bridle and making me listen to her - a great deal of her prophesying came true, [and] through she had no coin from me nor even thanks she continued calling after me flattering things. Twice afterwards $\mathrm{m}$ fortune was told in an amazing way by cards which an old friend of the family laid out mysteriously [...] Into one of these tumblers set before us we each broke an egg, letting the white only drop into the water, then watching what form it would take which should signify the occupation of our future spouses. My sister began the charm eagerly $[\ldots]$ 'You will marry a writer', And so I did! Now how did those eggs reveal it all? A most mysterious matter that! (HARDY, 1961 [1911], p. 39-41).

${ }^{16}$ We grew much interested in each other and I found him a perfectly new subject of study and delight, and he found a 'mine' in me, he said; he was quite unlike any other person who came to see us, for they were slow of speech and ideas! (HARDY, 1961 [1911], p. 58).

${ }^{17}$ I have some philosophy and mysticism, and an ardent belief in Christianity and life beyond this present one, all which makes any existence curiously interesting [...] (HARDY, 1961 [1911], p. 61). 
percepção que outras pessoas tinham de sua aparência, a sensação que passa não é tão diferente como aquela que sentiu nas ruas de Paris durante a sua lua de mel:

Eles em sua maioria consideravam ter mais cérebro e beleza do que eu, permitindo-
me ser 'atraente', no entanto, com um tipo de mente muito sentimental, que me serviu
muito bem ao longo da prova das ocorrências da vida. (HARDY, 1961 [1911], p. 4,
tradução nossa) ${ }^{18}$.

Essa mulher com seus setenta anos, que já mostrava insegurança com a sua aparência desde cedo, agora dentro de um casamento, no qual havia total estranhamento e falta de comunicação com seu esposo, precisa de um apoio. Todo esse misticismo e fé ardente, como ela mesma descreve, em termos junguianos, podem ser entendidos como a busca do Si-Mesmo.

A passagem para a terceira idade é vista pela Psicologia Analítica como sendo o momento no qual o processo de individuação - i.e. o tornar-se um ser único, alcançar uma singularidade profunda, tornando-nos o nosso próprio Si-mesmo - tem seu início. É nesse momento que as alterações e as disposições, que ocorrem tanto no mundo externo quanto no interno deste indivíduo, devido à sua autopercepção de envelhecimento, estabelecem uma crise, conhecida como a crise da meia idade ou a metanoia Junguiana. É nesse momento da vida que uma necessidade interna obriga o indivíduo a olhar para si de outro modo. As dinâmicas intrapsíquicas promovem mudanças na personalidade, nesta passagem da meia idade, que implicam na mudança de direção da libido e, consequentemente, do foco do ego, que não mais se encontra dirigido ao mundo externo, mas sim ao seu mundo interno. Foi essa mudança, caracterizada pelo apego que Emma Hardy criou com o mundo metafísico, que causou estranheza no seu já distante esposo. Na visão de Jung (1984), foi nesse momento que uma crise existencial se estabeleceu buscando promover um novo diálogo entre o ego, centro organizador da consciência, e o Self, centro organizador dos conteúdos inconscientes.

Jung (2010) acentua em sua obra que, após a meia-idade, é a fase mais importante do desenvolvimento, tendo trabalhado primordialmente com pessoas nesta faixa etária, a partir da segunda metade da vida, e colocado a individuação dentro dessa perspectiva como o encontro com o mistério, o insondável, a morte e a espiritualidade, isto é, a busca do significado pela vida. Na descrição da sua própria passagem, segundo Stein (2003), Jung destaca o papel da busca e encontro com o Si-Mesmo. Dessa maneira, a mudança, o aprofundamento místico

\footnotetext{
18 They mostly considered themselves to have more brains and beauty than I, allowing me to be 'attractive' however, with a very sentimental kind of mind, which mind served me very well through the proof of life's occurrences (HARDY, 1961 [1911], p. 4).
} 
presentes no percurso desta mulher do século XIX representam um dos meios presentes e disponíveis para o nosso processo de envelhecimento, a nossa busca do Si-Mesmo.

Segundo Stein (2003), para Jung, o Si-Mesmo é transcendente, no sentido de ser uma essência que se situa além do domínio subjetivo. A experiência com o Si-Mesmo é considerada a mais impessoal de todos os arquétipos (STEIN, 2003, p. 138). Dois exemplos vêm do próprio Jung, inicialmente com seu contato com o gnosticismo e o "encontro" através de um sonho que teve, no qual teve contato direto com aquele que chamaria de seu "mito pessoal", o encontro direto com a beleza real da natureza.

A passagem da meia-idade é caracterizada por aspectos específicos de uma nova etapa existencial em relação à individuação. Assim como na primeira, a crise após o meio da vida é interpretada por Jung como a necessidade de uma diferenciação do coletivo, em que ocorre uma transformação arquetípica de personalidade e necessidade de atingir o potencial existencial (BYINGTON, 1987); espera-se observar na passagem da meia-idade do indivíduo uma outra etapa de transformação interior, em geral, a denominada autorregulação por Jung. Com base na autoanálise realizada por Jung a respeito da sua passagem, podemos encontrar nos relatos e avaliações da Emma Hardy, que atravessam tal momento, a busca ou/e ressignificação do SiMesmo, isto é, do que Jung considera o centro transcendente responsável pela integridade da psique (STEIN, 2003). Dessa maneira, ao longo de toda essa interpretação metafísica no relato de Emma Hardy, encontramos indícios dessa busca.

\section{Considerações finais}

Eis a nossa primeira tentativa de dar voz a uma sombra ainda escondida atrás do esposo, consequência de uma sociedade vitoriana patriarcal. Por mais progressista que seu marido Thomas Hardy tenha sido, o que é fortemente evidente nas suas personagens femininas heroínas, na sua própria vida, quem um dia foi sua heroína era uma mulher na terceira idade isolada no sótão de casa, escrevendo suas memórias e passando os minutos restantes da sua existência ali. Mostramos, neste estudo, o poder que a autobiografia e o diário têm de oferecer novas interpretações, de dar possibilidade de nova voz aos banalizados e mal interpretados. Tentamos mostrar o lado humano de Emma Hardy, aquele presente em todos nós, por meio de uma interpretação via Psicologia Analítica e literatura sobre autobiografia, nos relatos de Emma Hardy. Imperfeita como todos nós, sim. Alguém que, segundo Kay-Robinson (1979), era 
também progressista na sua maneira de pensar ao lutar por uma atitude mais humana com os animais - era amante de gatos -, ao lutar pelo direito de voto das mulheres, ao se preocupar com a condição precária das mulheres que viviam nas ruas se prostituindo, e criticando a punição que apenas era direcionada para as mulheres.

\section{Referência}

ABRAHÃO, M. H. (org.) A aventura (auto)biográfica: teoria e empiria. Porto Alegre: EDIPUCRS, 2004.

BAILEY, J. O. Introduction. In: Emma Lavinia Hardy, Poems and religious effusions. Guernsey: J. Stevens Coxm, 1966.

BELZEN, J. A.; GEELS, A. Autobiography and the psychological study of religious lives. Amsterdam: Editions Rodopi B. V., 2008.

BYINGTON, C. Desenvolvimento da personalidade: símbolos e arquétipos. São Paulo: Ed. Ática, 1987.

BOIS, D.; RUGIRA, M. Relação com o corpo e narrativa de vida. In Souza, E. C. (org.) Autobiografias, histórias de vida e formação: pesquisa e Ensino. Porto Alegre: EdiPUCRS, 2016.

EAKING, P. J. Fictions in autobiography: studies in the art of self-invention. Nova Jersey: Princeton University Press, 1985.

EAKIN, P. J. How our lives become stories: making selves. Londres: Cornell University Press, 1999.

EAKIN, P. J. The ethics of life writing. Londres: Cornell University Press, 2004.

HARDY, E. L. Poems and religious effusions. Guernsey: J. Stevens Coxm 1966 [1911].

HARDY, E.L. Some Recollections. Londres: Oxford University Press, 1961 [1911].

JUNG, C. G. A psicologia do inconsciente. Petrópolis: Editora Vozes, 1984.

JUNG, C. G. O eu e o inconsciente. Petrópolis: Editora Vozes, 1987.

JUNG, C. G. A Natureza da Psique. In: Obras Completas de C. G. Jung (Vol. VIII/2). Petrópolis: Vozes, 2010.

KAY-ROBINSON, D. The first Mrs. Thomas Hardy. Nova York: St. Martin's Press, 1979.

LARROSA, J. Notas sobre narrativa e identidad (a modo de presentación). In: ABRAHÃO, M. H. (org.) A aventura (auto)biográfica: teoria e empiria. Porto Alegre: EDIPUCRS, 2004. 
MANFORD, A. Note on the text. In: HARDY, T. A pair of blue eyes. Oxford: Oxford University Press, 2005.

MOSQUERA, J. J.; STOBÄUS, C.D. Narrativas de vida: fundamentos de uma dimensão metodológica. In: ABRAHÃO, M. H. (org.) A aventura (auto)biográfica: teoria e empiria. Porto Alegre: EDIPUCRS, 2004.

POPKIN, J. D. Philippe Lejeune, explorer of the diary. In: POPKIN, J. D.; RAK, J. (org.) Ondiary. Monoa: University of Hawai Press, 2009 [1938].

STEIN, M. O Mapa da Alma. São Paulo, Cultrix, 2003.

TAYLOR, R. (org.) Emma Hardy diaries. Manchester: Carcanet New Press, 1985.

Recebido em: 10/07/2019

Aceito para publicação em: 25/11/2019 